\title{
Imaging of Esophageal Cancer - Pictorial Essay
}

\section{Subbarao Kakarla*}

Professor, Chairman KREST, Hyderabad, Telangana, India

*Corresponding Author: Subbarao Kakarla, Professor, Chairman KREST, Hyderabad, Telangana, India
Received: January 20, 2020

Published: April 27, 2020

(C) All rights are reserved by Subbarao

Kakarla.

\section{Abstract}

The incidence of Esophageal Cancer is increasing while stomach cancer is decreasing. Imaging plays a major role in the early diagnosis, prognosis and management. The imaging methods include conventional radiology of the chest, contrast studies of the esophagus, Ultrasonography, CT, MRI and PET CT. Fluoroscopy with spot films of contrast studies is essential in detecting early lesions. Major imaging features include ulceration, filling defect, infiltration, obstruction, and involvement of the neighbouring structures. These features are illustrated abundantly. Apart from carcinoma of the esophagus, other malignancies include spindle cell carcinosarcoma, malignant gist, lymphoma, melanoma, etc.

Keywords: Esophageal Cancer; Imaging by Ultrasonography; CT; MRI; PET CT; Perforation; Stents; Benign Tumors of Esophagus

\section{Introduction}

Patients with esophageal carcinoma tend to present with recent onset and rapidly progressive dysphagia with associated weight loss. Historically, the most common pathologic type of esophageal cancer was squamous cell carcinoma. In recent years, however, there has been an overwhelming increase in the prevalence of esophageal adenocarcinoma. Adenocarcinoma is most often found in the distal esophagus and may arise in Barrett esophagus or as gastric cancer invading the distal esophagus. Regardless of pathologic type, esophageal cancer can appear image wise as infiltrative, ulcerative, polypoid, and/or varicoid at esophagography. Fluoroscopy and contrast studies play a major role while endoscopic Ultrasonography depicts the local lesion with extension into the layers. CT, MRI and PET CT have the advantage of detecting metastatic spread (Table 1). Endoscopy has the advantage of taking a biopsy for histopathological studies. The predisposing factors for esophageal cancer include alcohol, smoking, achalasia, asbestosis, Barrett esophagus, ionizing radiation, caustic stricture/lye stricture, obesity and Human Papilloma Virus (HPV).

Histologically, majority of the cases are of squamous cell carcinoma. Next in order is adenocarcinoma. Other types include mucoepidermoid carcinoma, adenoid cystic carcinoma, and spindle cell squamous carcinoma. Macroscopically polypoid, "apple core" lesion, ulcerating, infiltrating and stricture types are noted.

\section{Case Report and Discussion}

Conventional Chest radiograph may give indirect signs of presence of Cancer [1-3]. Imaging features include the following (Table 2).

Conventional radiology of the chest is important to depict the complications as well as extension of the lesion into mediastinum and other structures (Figure $1 \mathrm{a}$ to $1 \mathrm{~h}$ ).

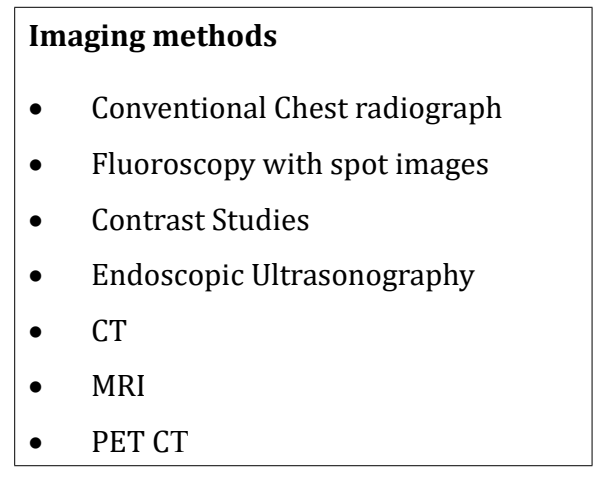

Table 1

- Widened azygo-esophageal recess with convexity toward right lung (in 30\% of distal and mid-esophageal cancers)

- Thickening of posterior tracheal stripe and right paratracheal stripe $>4 \mathrm{~mm}$ (if tumor located in the upper third of esophagus)

- Tracheal deviation or posterior tracheal indentation/mass

- $\quad$ Retrocardiac or posterior mediastinal mass

- $\quad$ Esophageal air-fluid level

- $\quad$ Lobulated mass extending into gastric bubble (Kirklin sign)

- $\quad$ Repeated aspiration pneumonia (with tracheo-esophageal fistula)

\section{Table 2}

\section{Fluoroscopy and barium studies}

They reveal ulceration, polypoidal filling defect, infiltration, partial obstruction, "apple core" deformity with overhanging edges and fistula formation. The barium is specially prepared with thin and thick paste for study of mucosal relief. Occasionally the barium may be aspirated. In order to avoid it, water soluble non ionic solutions such as Gastrograffin may be used. Air contrast studies have 


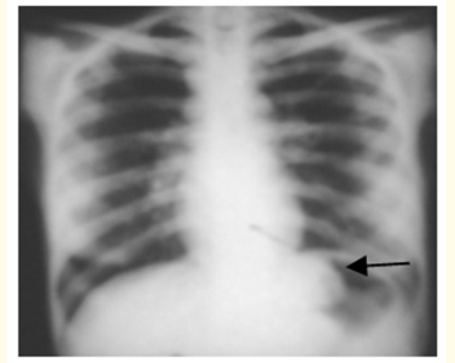

Figure 1a: Chest radiograph showing a large mass in the stomach bubble (arrow) due to Carcinoma.

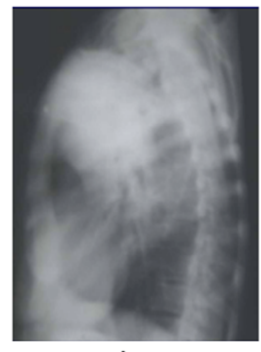

b

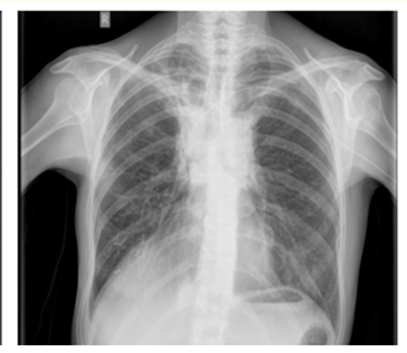

Figure 1b and 1c: b: Carcinoma of the esophagus with anterior mediastinal nodes. c: Post radiation therapy, fibrosis of the lungs.

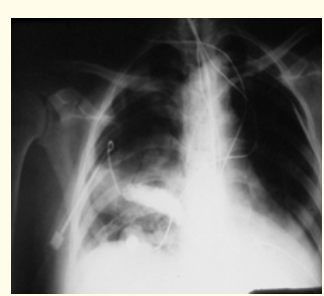

Figure 1d: Ruptured esophagus into right pleural cavity.

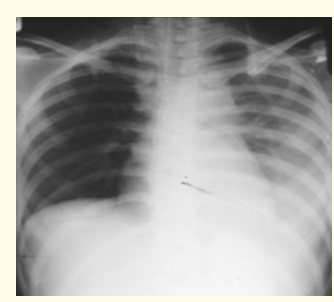

Figure 1e: Ruptured CA of esophagus with left pleural effusion.

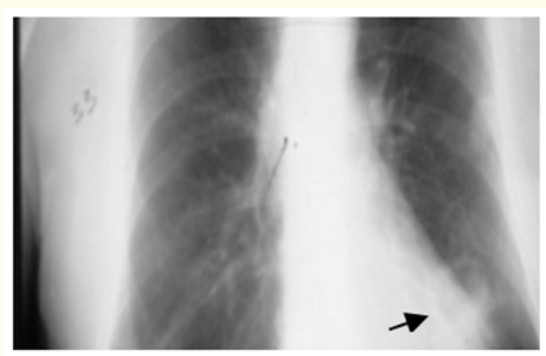

Figure 1f: CA of Esophagus with cavitating lung METS.

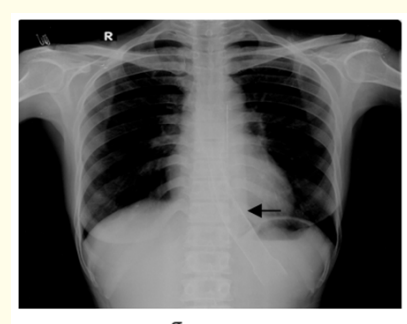

$\mathrm{g}$

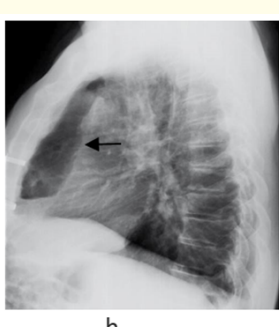

$\mathrm{h}$
Figure 1g and $1 \mathrm{~h}$ : g: Esophageal stent. h: Gastric pull through the anterior mediastinum. been introduced by Japanese and are quite useful in detecting early lesions [4-6]. Double contrast study shows the following features (Table 3).

- Small polypoidal filling defect

- Plaque like

- Focal irregularity

- Small sessile polyps

- Superficial spreading

Table 3: Double contrast study.

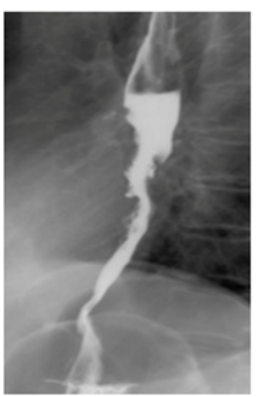

a

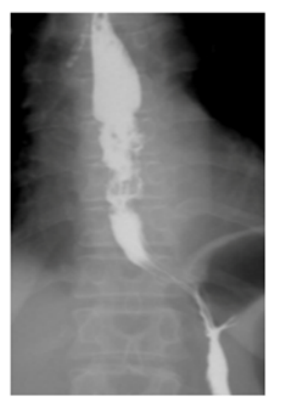

b
Figure 2a and $2 \mathbf{b}$ : CA of esophagus showing irregularity of the Barium column.

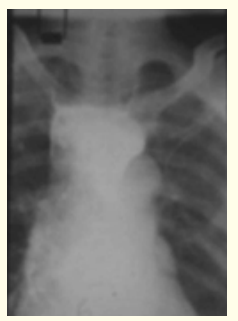

Figure 2c: Barium fluid level in the esophagus due to obstructive lesion of carcinoma.
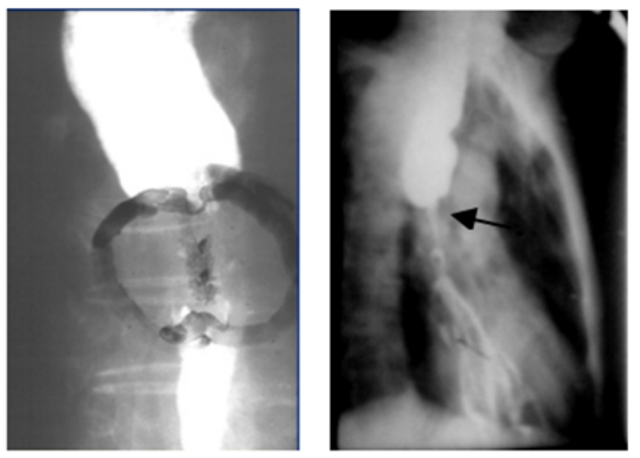

Figure 2d: Ba- Annular carcinoma with apple core deformity, b- Recurrence after resection and esophagogastrostomy.

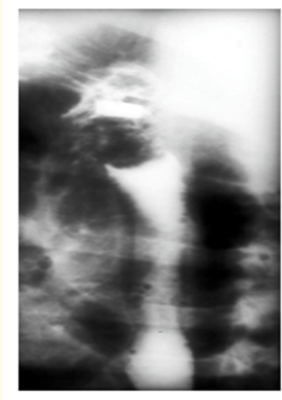

e

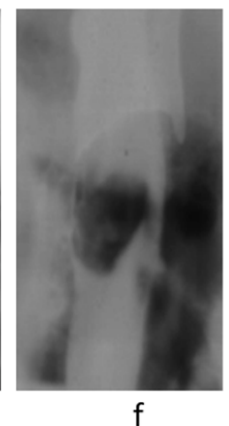

$f$
Figure 2e and 2f: Polypoidal filling defect due to Carcinoma. 


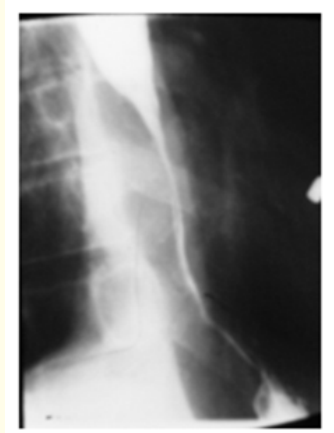

a

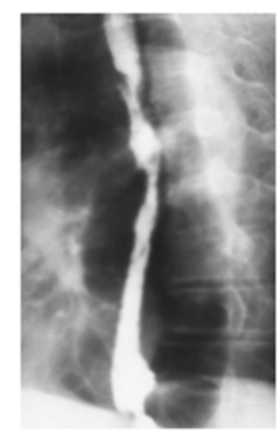

b
Figure 2g: a- Carcinoma esophagus with "Rat Tail" appearance, b- resembling corrosive stricture.

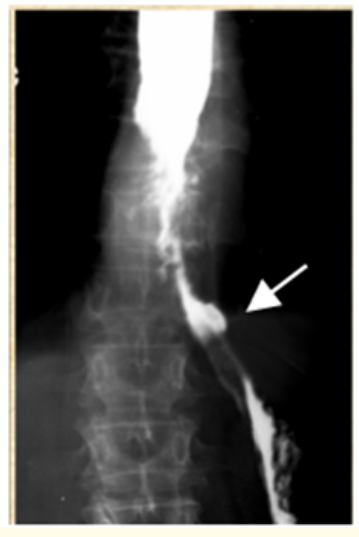

Figure 2h: Carcinoma of the lower end of esophagus extending into stomach.

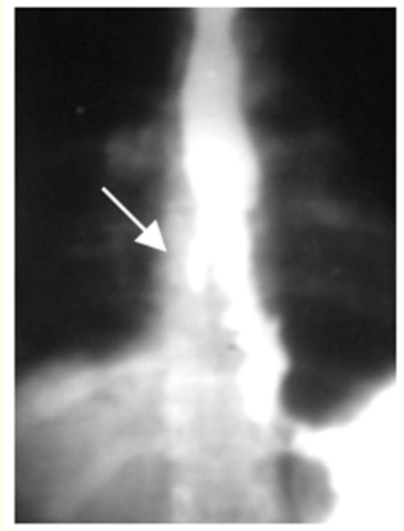

Figure 2i: Barium swallow showing perforation into mediastinum.

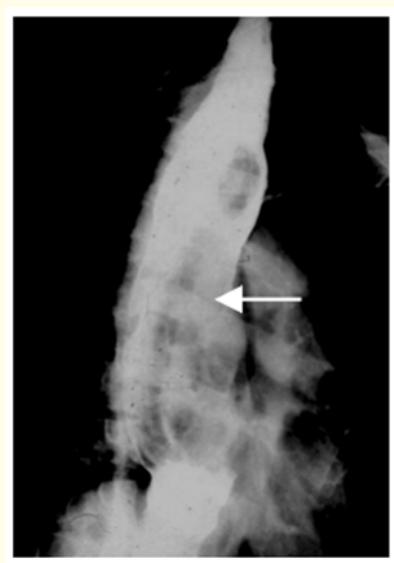

Figure 2j: Varicoid Carcinoma showing tortuous filling defects.

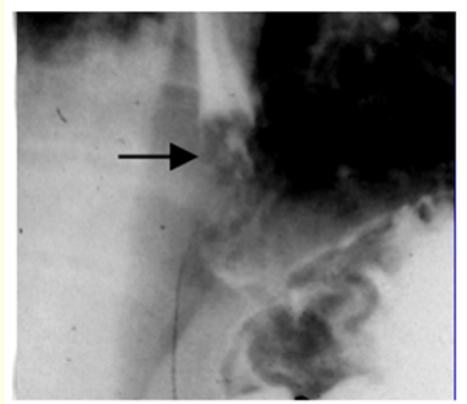

Figure 2k: Carcinoma of the stomach extending into the esophagus.

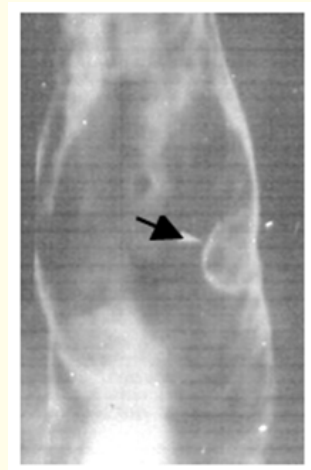

Figure 3a: Air contrast studies showing plaque like lesion in CA of esophagus.

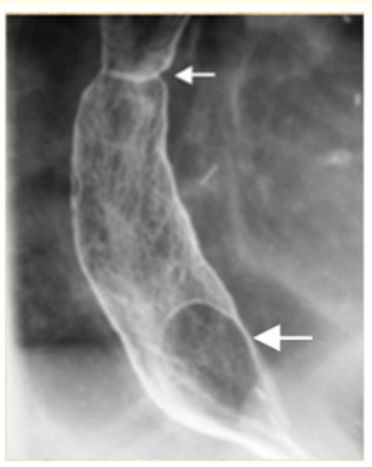

Figure 3b: Barrett's esophagus with Carcinoma.

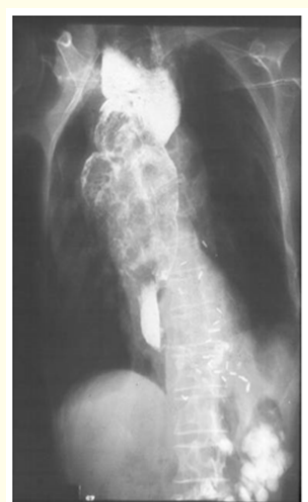

a

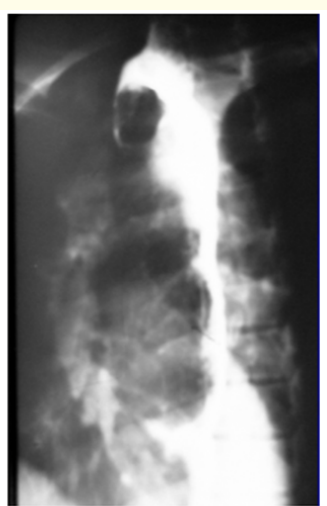

b
Figure 4a and 4b: Spindle cell Carcinoma - Large polypoidal defect in spindle cell carcinosarcoma. 


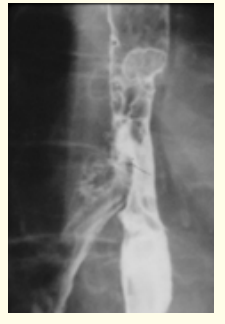

Figure 5a: Esophageal Carcinoma, Perforation into trachea with contrast in the bronchus.

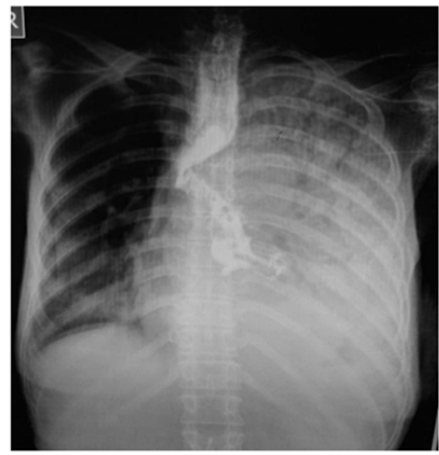

b

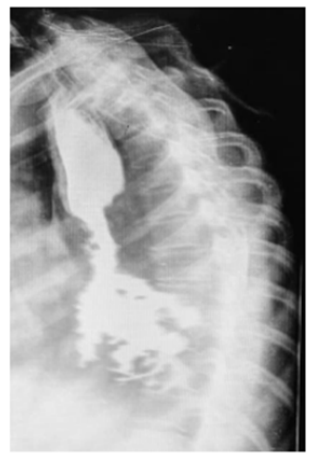

C
Figure 5b and 5c: Esophagobroncheal fistula due to carcinoma of the esophagus.

\section{Endosonography}

This is another imaging modality where all the five layers are clearly detected. Endoscopic ultrasound (EUS) is a procedure combining the range of endoscopy with the diagnostic abilities of ultrasound (Table 4). Endoscopic ultrasound can be used for local TNM staging of esophageal cancer to determine the local invasion of the tumor through the normal esophagus. Any infiltrative lesion involved in the layers is demonstrated $[11,12]$.

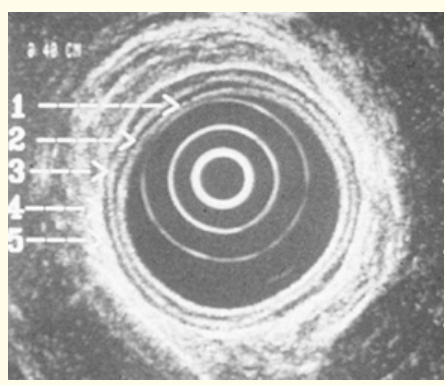

Figure 6a: Endosonography of a normal esophagus.

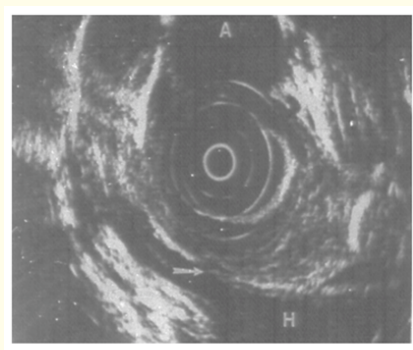

b

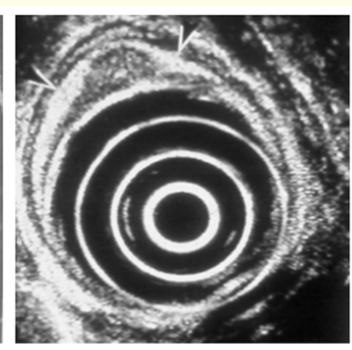

C
Figure 6b and 6c: Endosonography showing infiltrative Carcinoma.

\begin{tabular}{|ll|}
\hline 1. & Superficial mucosa - Hyper \\
2. & Deep mucosa + Musc. Mu - Hypo \\
3. & Sub mucosa + Musc. Pro - Hypo \\
4. & Muscularis propria - Hyper \\
5. & Adventitia - Hyper
\end{tabular}

Table 4: Endosonography (Layers of esophageal wall).

\section{CT examination}

It should extend from the thoracic inlet through the liver. Routine oral contrast material should be administered. This may be positive contrast agent, such as dilute barium, or a negative intraluminal contrast medium, such as water. A low-density $3 \%$ weightfor-weight esophageal barium paste may be administered immediately prior to scanning [10-13].

C.T. scanning for Esophageal Carcinoma assessing Tumor bulk and other features (Table 5).

- Periesophageal fat planes

- Monitoring tumor response

- $\quad$ Spread to contiguous structures

- Metastasis to lung, liver and adrenal

- Invasion of Adjacent mediastinum, Trachea, Bronchi, Aorta, pericardium, Nodes

Table 5

CT Features of Esophageal Carcinoma - Demonstrates thickening, irregularity, involvement of aorta and other mediastinal structures [7-9].

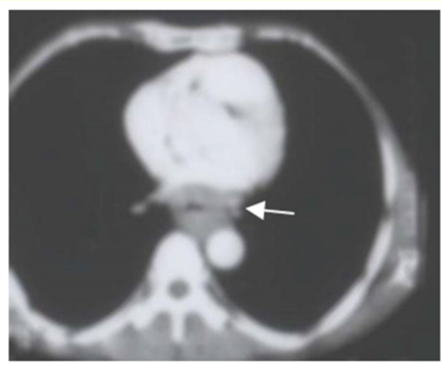

Figure 7a: CT Showing circumferential thickening in CA Esophagus.

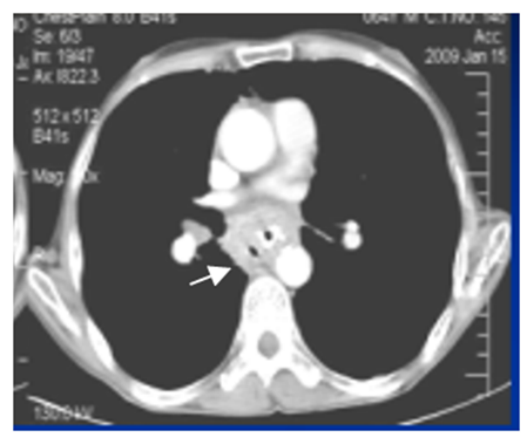

Figure 7b: CT showing Perforation of the esophagus due to Carcinoma. 


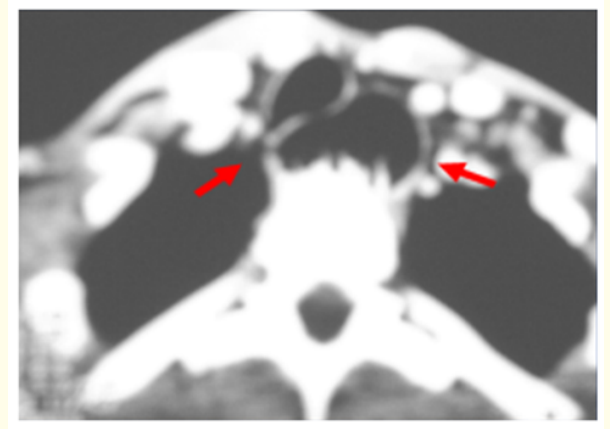

Figure 7c: CT showing CA of esophagus with proximal dilatation with deviation of the trachea.

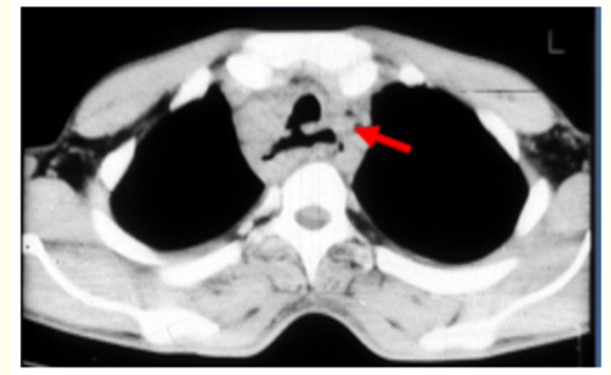

Figure 7d: CT showing tracheoesophageal fistula.

Esophageal cancer

Staging - MRI/PET - CT.

MRI has few advantages over CT.

PET CT: PET/CT is useful for detecting esophageal primary tumors yet it has little role in helping determine the specific $\mathrm{T}$ classification because it provides limited information about the depth of tumor invasion. PET/CT is also superior to CT for detecting lymph node metastases and can depict metastases in normal-sized lymph nodes through the uptake of FDG. PET/CT has a primary role in the depiction of distant sites of metastatic disease. The most common sites of distant metastases detected at PET (but frequently missed at CT) are the bones and liver [14-17].

\section{Differential diagnosis}

Fibrovascular polyps

These are benign nonneoplastic masses. Barium studies reveal smooth but lobulated intraluminal masses that originate in the lower cervical esophagus and have variable sizes and distal extents, with an average length of $15 \mathrm{~cm}$ (Figure 8).

In the differential diagnosis of filling defects in esophagus, melanoma and metastasis are to be considered.

\section{Conclusion}

Incidence of Carcinoma of the esophagus is taking over carcinoma of the stomach. Imaging methods are mentioned and the importance of imaging of carcinoma of the esophagus in early diagnosis, assessing prognosis, and in management is pointed out. Importance of chest radiograph is stressed. Endosonography plays a major role. Palliative treatment with esophageal stents is shown. Complications are mentioned with few differential diagnostic points.

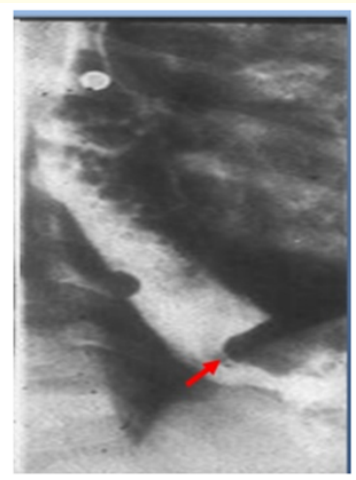

Figure 8: Metastasis to Esophagus from carcinoma of the breast.

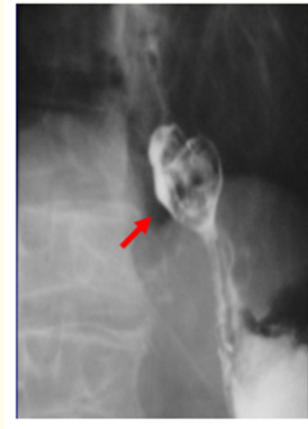

a

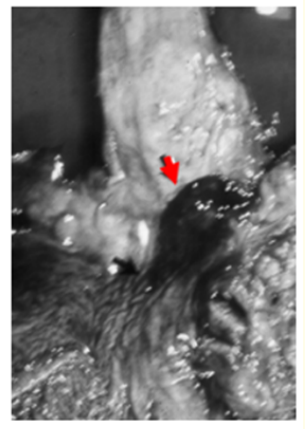

b
Figure 9a and 9b: Melanoma, a - polypoidal filling defect,

$$
\mathrm{b} \text { - specimen. }
$$

In the differential diagnosis of benign lesions, fibrovascular polyp and gastrointestinal tumors (gists) are to be considered. If the diameter of gist is $>5 \mathrm{~cm}$, malignancy should be thought of.

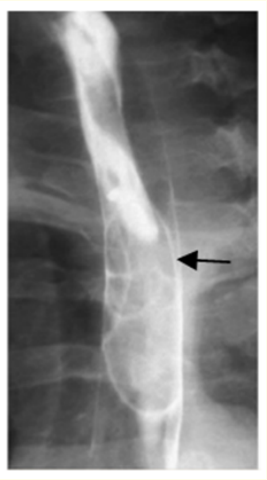

Figure 9c Fibrovascular polyp of the esophagus with elongated filling defect.

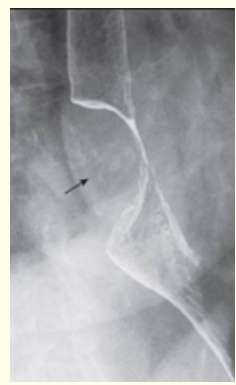

Figure 9d: Gist intramural filling defect- malignancy depends upon the size. 


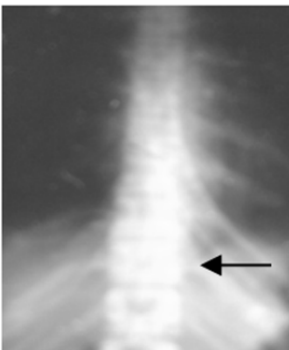

a

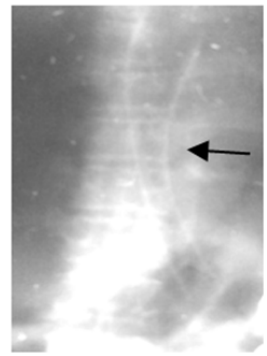

b
Figure 10a and 10b: Esophageal stents, a- self expanding metallic stent (flamingo) b- another stent.

\section{Acknowledgements}

NIMS, KIMS, KREST Museum Hyderabad

\section{Conflicts of Interest}

Author declares no conflicts of interest.

\section{Bibliography}

1. Mostafa El-Feky and Frank Gaillard. "Esophageal carcinoma”.

2. Margolis ML., et al. "Pulmonary nodules in patients with esophageal carcinoma". Journal of Clinical Gastroenterology 26.4 (1998): 245-248.

3. Bejvan SM and Godwin JD. "Pneumomediastinum: old signs and new signs". American Journal of Roentgenology 166 (1996): 1041-1048.

4. Rachel B Lewis., et al. "From the Radiologic Pathology Archives: Esophageal Neoplasms: Radiologic-Pathologic Correlation". RadioGraphics 33.4 (2013).

5. Aletta Ann Frazier. "Spectrum of Esophageal Tumors".

6. Levine MS and Halvorsen RA. "Esophageal carcinoma". In: Gore RM, Levine MS, Laufer I, eds. Textbook of Gastrointestinal Radiology. Philadelphia: WB Saunders Co (1994): 446478.

7. Maurits J Wiersema., et al. "Endoscopic ultrasound in esophageal carcinoma".

8. Mark Thurston and Marcin Czarniecki. "Endoscopic ultrasound".

9. Heidemann J., et al. "Accuracy of endoscopic ultrasonography in preoperative staging of esophageal carcinoma". Digestive Surgery 17.3 (2000): 219-224.

10. Kavita U Vaishnav., et al. "Role of CT Scan in Staging of Carcinoma of Esophagus - A Study of 100 Cases". Gujarat Medical Journal 69.1 (2014).

11. Revathy B Iyer., et al. "Diagnosis, Staging, and Follow-Up of Esophageal Cancer". American Journal of Roentgenology 181.3 (2003): 785-793.
12. Rankin SC., et al. "Computed tomography and positron emission tomography in the pre- operative staging of oesophageal carcinoma”. Clinical Radiology 53.9 (1998): 659-665.

13. Mazzeo S., et al. "Multidetector CT and virtual endoscopy in the evaluation of the esophagus". Abdominal Imaging 29.1 (2004): 2-8.

14. Piotr Sadej., et al. "AIRP Best Cases in Radiologic-Pathologic Correlation: Spindle Cell Carcinoma of the Esophagus". RadioGraphics 31.7 (2011).

15. Kim K., et al. "Evaluation of lymph node metastases in squamous cell carcinoma of the esophagus with positron emission tomography". The Annals of Thoracic Surgery 71.1 (2001): 290-294.

16. Kwee RM., et al. "PET with Fluorodeoxyglucose F 18/Computed Tomography in the Clinical Management and Patient Outcomes of Esophageal Cancer". PET Clinic 10.2 (2015): 197-205.

17. Goense L., et al. "Diagnostic performance of 18F-FDG and PET/ CT for the detection of recurrent esophageal cancer after treatment with curative intent: a systematic review and meta-analysis". The Journal of Nuclear Medicine 56.2 (2015): 995-1002.

\section{Assets from publication with us}

- Prompt Acknowledgement after receiving the article

- Thorough Double blinded peer review

- Rapid Publication

- Issue of Publication Certificate

- High visibility of your Published work

Website: https://www.actascientific.com/

Submit Article: https://www.actascientific.com/submission.php Email us: editor@actascientific.com

Contact us: +919182824667 